\title{
Poverty and Nutritional Health of the Child: Some Evidence from 2005 Demographic and Health Survey of Congo
}

\author{
Samuel Ambapour ${ }^{1}$, Jean Christophe Okandza ${ }^{2}$, Hylod Armel Moussana ${ }^{1}$ \\ ${ }^{1}$ Institut National de la Statistique, Brazzaville, République du Congo \\ ${ }^{2}$ Faculté des Sciences Economiques, Université Marien Ngouabi, Brazzaville, République du Congo \\ Email: ambapour_samuel@yahoo.fr, jcokandza@gmail.com, hylodmoussana@yahoo.fr
}

Received 27 September 2015; accepted 10 November 2015; published 13 November 2015

Copyright (C) 2015 by authors and Scientific Research Publishing Inc.

This work is licensed under the Creative Commons Attribution International License (CC BY). http://creativecommons.org/licenses/by/4.0/

(c) (i) 0 pen Access

\begin{abstract}
The objective of this study is to identify the ways in which poverty could affect the nutritional health of the child and to analyze the strength of these links. On the whole, it appears that the relationship between poverty (measured by the wealth index) and health of the child (measured by an anthropometric index) is positive and highly significant.
\end{abstract}

\section{Keywords}

Wealth Index, Nutritional Health of the Child, Height for Age, Z-Score

\section{Introduction}

The relationship between health and poverty is often described in the literature as very complex, still poorly identified and reciprocal. In the particular case that interests us, this relationship has a dual aspect [1]. On one hand, economic growth (which is assumed to be able to eradicate poverty) led to reducing malnutrition. On the other hand, nutrition is a key ingredient of human capital, considered as a fundamental factor of economic growth. In this paper, we are particularly concerned about the nutritional health of children under five years of age. In fact, protecting health during childhood is necessary because compromised health at a young age may have consequences during adulthood: lower productivity and income, reduced social participation, no visible "return" on the family's investment in the child's health [2].

To characterize the health status of children, previous research used anthropometric data (size, children's weight); because these data are simple, accurate, and have been the subject of a consensus for estimating the malnutrition of children. In this anthropometric approach, we have focused on the delayed growth factor as 
measured by the long term indicator of height for age. With regard to poverty, a non-monetary approach is used: a wealth index is built using durable goods owned by households. The indicator thus obtained is considered as a proxy for long-term household income.

In a study of the determinants of the health of the child, the empirical work shows that there is a positive link between household resources and the nutritional status of the child. However, the intensity of this connection may vary from one country to another: for example, it is strong in the case of Benin [3], moderate in Bangladesh [4] and low in Mali [5]. In the case of Congo, this relationship will be analyzed in two phases. In a first phase, we present the results of the direct relationship between poverty and the nutritional status of the child, and in a second phase, the results of the determinants of this status, following the introduction of control variables.

This text is set forth as follows: The following chapter presents the origin of the data; it also describes in detail the variables of the study. In the third chapter, we specify the model chosen to study the relationship between poverty and nutritional health of the child. The fourth chapter provides the results of the econometric estimates.

\section{Data and Variables}

\subsection{Data}

This work is based on the Demographic and Health Survey of Congo carried out in 2005 by the National Centre for Statistics and Economic Studies with technical assistance from ORC Macro, an American cooperating institution in support of this type of investigation [6]. The overall objective of this first demographic and health survey was to determine the demographic and health indicators essential to the establishment of policies and programs, and more particularly to finalize the Poverty Reduction Strategy Paper and to follow-up on the Millennium Development Goals. This investigation, which is a rich source of information, appears limited, however, when it comes to studying monetary poverty. In these conditions, the relationship between poverty and the nutritional health of the child will be based on a non-monetary conceptualisation of poverty.

This being said, during the study, all children under five years present in the household selected, had to be weighed and measured. Thus, the results on the nutritional status are based on a sample of 4472 children.

\subsection{Specification of Variables}

We begin by first defining the nutritional status of the child, then by identifying the main determinants of this state grouped into three categories.

\subsubsection{The Nutritional Status of the Child}

There is no single indicator of the nutritional status per se. We generally use approximate measures which provide information on the nutritional status through their involvement in various processes or physiological functions [7]. In relation to young children, it is based on the anthropometric measures [8]-[10] considered as objective health status indicators [11]. In this case, we can typically identify three indices: height in relation to age; weight compared to height and weight in relation to age. Each index is expressed in terms of the number of standard deviation units (SD) in relation to the median of the international reference population of NCHS/CDC/WHO.

In our study, we have focused on the height for age index1. This index is considered by specialists [7] as a stable, complex indicator, which allows you to judge on the basis of the evolution of a more concise set of factors of family life, and it is for that reason, it gradually supplanted the other two. This is a key indicator of the quality of life in developing countries [12] [13]. Therefore, it will be considered here as a proxy for the nutritional status of the child and is used as a variable explained in our model.

Table 1 presents the percentage of children with malnutrition measured by the anthropometric index heightage and against some sociodemographic characteristics. Below, the sample that we will consider is composed of 3824 children under five years of age, of which 1851 are girls and 1973 are boys and for who we have the complete data.

\subsubsection{The Individual Characteristics of the Child}

Among the variables specific to the child we have retained a number (depending on the availability of data) that

${ }^{1}$ In this text, the following terms are considered equivalent: nutritional status, height for age, z-score. 
Table 1. Children nutritional status: percentage of children under five years of age, with malnutrition (as defined by anthropometric index height/age) and distribution of socio-demographic characteristics.

\begin{tabular}{|c|c|c|c|c|c|c|c|}
\hline \multirow{2}{*}{$\begin{array}{c}\text { Socio-demographic } \\
\text { Characteristics }\end{array}$} & \multicolumn{2}{|c|}{ Height by Age } & \multirow{2}{*}{$\begin{array}{l}\text { Number } \\
\text { of children }\end{array}$} & \multirow{2}{*}{$\begin{array}{c}\text { Socio-demographic } \\
\text { Characteristics }\end{array}$} & \multicolumn{2}{|c|}{ Height by age } & \multirow{2}{*}{$\begin{array}{l}\text { Number of } \\
\text { children }\end{array}$} \\
\hline & $\begin{array}{l}\text { Percentage of } \\
<-3 S D\end{array}$ & $\begin{array}{l}\text { Percentage of } \\
<-2 \text { SD }\end{array}$ & & & $\begin{array}{c}\text { Percentage } \\
\text { of }<-3 S D\end{array}$ & $\begin{array}{c}\text { Percentage } \\
\text { of }<-2 S D\end{array}$ & \\
\hline Children Age & & & & Weight at birth & & & \\
\hline$<6$ & 1.5 & 4.7 & 470 & & & & \\
\hline $6-9$ & 3.0 & 10.2 & 359 & Very small & 24.1 & 40.8 & 85 \\
\hline $10-11$ & 3.2 & 17.4 & 136 & Small & 14.4 & 35.7 & 250 \\
\hline $12-23$ & 16.1 & 34.3 & 858 & Normal o big & 9.2 & 23.6 & 3477 \\
\hline $24-35$ & 11.0 & 28.1 & 959 & Not defined & 17.9 & 34.4 & 183 \\
\hline $36-47$ & 13.9 & 30.1 & 910 & & & & \\
\hline $48-59$ & 11.5 & 30.9 & 780 & & & & \\
\hline Sexe & & & & Place of residence & & & \\
\hline Masculine & 12.3 & 27.6 & 2279 & Urban & 9.2 & 22.1 & 2045 \\
\hline Feminine & 9.3 & 24.3 & 2194 & Rural & 12.1 & 29.2 & 2427 \\
\hline Order of birth & & & & Region & & & \\
\hline 1 & 11.9 & 27.1 & 950 & Brazzaville & 11.7 & 23.7 & 1218 \\
\hline $2-3$ & 8.7 & 23.2 & 1627 & Pointe Noire & 5.0 & 19.2 & 592 \\
\hline $4-5$ & 9.6 & 25.2 & 851 & South & 11.5 & 27.6 & 1723 \\
\hline $6+$ & 13.5 & 28.2 & 581 & North & 11.9 & 30.3 & 940 \\
\hline Mother's Age & & & & Mothers' level of education & & & \\
\hline $15-19$ & 10.2 & 26.0 & 1051 & None & 19.4 & 33.9 & 385 \\
\hline $20-24$ & 13.2 & 28.5 & 1176 & Primary & 12.2 & 29.3 & 1502 \\
\hline $25-29$ & 9.8 & 24.4 & 914 & Secondary $1^{\text {st }}$ cycle & 7.7 & 21.2 & 2193 \\
\hline $30-34$ & 8.3 & 22.4 & 689 & Secondary 2d cycle or above & 5.6 & 22.0 & 66 \\
\hline $35-49$ & 11.5 & 27.4 & 643 & & & & \\
\hline $\begin{array}{l}\text { Period between } \\
\text { births (in months) }\end{array}$ & & & & Quintiles of economic wellbein & & & \\
\hline First born & 12.0 & 27.2 & 960 & Poorest & 13.5 & 31.9 & 1041 \\
\hline$<24$ & 13.0 & 30.1 & 388 & Second Q & 9.9 & 27.2 & 1034 \\
\hline $24-47$ & 11.5 & 27.0 & 1546 & Medium & 11.3 & 24.6 & 927 \\
\hline \multirow[t]{3}{*}{$48+$} & 6.3 & 19.6 & 1115 & Fourth Q & 10.8 & 23.7 & 780 \\
\hline & & & & richest & 7.3 & 19.7 & 690 \\
\hline & & & & Total & 10.8 & 26.0 & 4472 \\
\hline
\end{tabular}

we propose to define ${ }^{2}$.

\section{1) The age and gender of the child}

For a child of a given gender, age is an important determinant of the individual growth. As age increases, the nutritional status of children in the developing countries deteriorates because of the cumulative effects of the lack of nutritional intake [14]. Generally, we seek to test the hypothesis that, up to a certain age, malnutrition tends to intensify, and beyond this age the trend reverses with the change in food intake.

Recent research [15] suggests that the gender of a child has important and extended effects on parental behaviours and family results. Abundant literature indicates a preference for male children in many developing countries and particularly in Asia [16] [17]. Malnutrition is therefore more frequent among girls than among boys [18]. In Africa, according to a study conducted by the OECD [19], and contrary to what one might imagine, girls are almost always preferred. We will therefore test this hypothesis of the absence of discrimination against girls [20] in our sample which is composed of $48.4 \%$ girls and $51.6 \%$ boys.

\section{2) The birth rank}

Some studies take into account the order of births as an explanatory factor of child malnutrition [4] [14] [16]. It is suggested that the birth rank seems to have a significant effect on the quality of life, including on infant mortality [17]. However, it may be noted that the expected effect of birth order is ambiguous. Some argue that the first-born often have an advantage. Others, on the contrary argue that children of lower rank are sometimes underweight [21]. In addition, some research demonstrates that children of higher rank are poorly fed. The rela-

${ }^{2}$ In developing countries, breastfeeding plays an important role in the child's growth. Unfortunately, lacking comprehensive data, this variable is not taken into account in our study. 
tionship between the nutritional status of the child and birth order is therefore complex [14] [18] [22] and may depend on household resources (how they are spread over time), biological and cultural factors.

\section{3) The interval of births}

A short interval between births can cause a physiological impairment of the mother, such that the child may have a delay in weight and size at birth. The more closely spaced the births, the lower the breast milk quality, particularly under the effect of physical exhaustion of the mother. It is obvious that mothers who must raise two children at the same time give them less care. Accordingly, it is therefore expected that the interval of birth can have a significant impact on the levels of malnutrition.

\section{4) The presence of a twin}

It has been found that the absence of a twin significantly improves size. We explain this biological fact in the following manner: each twin often suffers at birth from a handicap that must be compensated for by food and appropriate care [19].

\section{5) The number of children in the household}

We want to know if the integration of the child with its siblings has an impact on its growth. To this effect, two variables are tested: the number of children under five years of age and the number of children in the household ${ }^{3}$. A priori, the expected effect of an increase in these variables would be to deteriorate the child's health. The presence of a high number of children under five years of age increases the mother's load in terms of care and therefore should have a negative impact. However, one could imagine, in the case of the variable "number of children in the household" that the older children can take care of the younger children when they are not yet working, providing resources for parents if they work [23]. In this case, this variable should have a positive influence.

\subsubsection{The Characteristics of the Parents and the Household}

\section{1) The mother's age at the first birth}

The expected effect of the mother's age at the first birth upon the size of the child and on its probability of having a normal growth is ambiguous. From a biological point of view, one would assume that the physical conditions of a young mother are better than those of an older mother. In these conditions, a positive relationship is suspected. If age is considered as a variable approached from the accumulation of experience in terms of care, one might think that a mother who is too young is probably less mature and less experienced. In this case, one can expect a negative relationship ${ }^{4}$.

\section{2) The mother's health}

Among the variables characterising the state of the mother's health, certain previous work continues [24] [25], among other things, the body mass index as an explanatory factor favourable to the child's growth. It is defined by weight in kilograms divided by the square of height in meters. According to Fogel [26], the extreme values of this index (less than 18.5 a sign of chronic energy deficiency or more than 30 a sign of obesity) are for the mother, respectively indicators of poor health or early morbidity. Grira [4] indicates that this index could reflect the availability of food within the household and that a reduction in the supply of food would result in a lower body mass index for the mother and therefore an elevated risk of malnutrition for the child.

\section{3) The mother's family situation}

Three situations are distinguished: the monogamous family, the polygamous family and the single parent family (the mother lives alone). Concerning the polygamous family, one might suspect a negative impact of this variable on the nutritional status of the child. In effect, one might think that polygamous fathers would have more of a burden than others, meaning many more children and adults to feed. One could also imagine a woman living alone has fewer resources. In this case, one might expect a negative impact on the growth of the child. However, in the study already cited, Morrison and Liskens [19] note that in most countries, mothers who live alone are usually fewer in number and are distinguished from others by a higher level of education or the possession of durable goods. In these conditions, a positive impact on the growth of the child cannot be ruled out.

\section{4) The parents' education}

There is extensive literature on the positive role of parents' education of on the health of children. With respect to the work of Schult [27], we see five main channels of influence of parental education on the children's

\footnotetext{
${ }^{3}$ The variable "number of children born before the child considered" is sometimes used.

${ }^{4}$ In this respect, there is also the effect of the composition of the household in which the mother resides. It is quite frequent, including in the Congo, that children are primarily supported by their grand-mothers in cases where the mother is of a very young age.
} 
health [8] [24] [28] [29]. Firstly, education has a direct effect on the acquisition of knowledge in the field of health and hygiene. Secondly, education increases general skills in reading and logical thinking, which enables one to fully understand instructions from the nursing staff and to better manage diseases by taking initiatives. Thirdly, education increases the probability of obtaining a job, of increasing the total income, which in the end allows one to improve infant health. Fourthly, a better education increases the opportunity cost of work time and thus reduces the time spent caring for the children and breastfeeding. Finally, education can affect the preferences of parents. They may decide to limit the number of births in order to have only children in good health.

In this study, we chose the mother's education, because many studies have shown that the number of years of education of the husband/spouse had little effect on the health of the child. Moreover in Africa, it is the mother who has the primary responsibility for childcare. In fact, the most decisive aspect for the mother is that she knows how to read and write. If this is the case, there would be no correlation between the child's health and the mother's educational level. This hypothesis will therefore be tested. Its non-acceptance would mean that an educated woman would develop greater capability for childcare in particular if she has training in nutrition. In this context, we have introduced a variable of the mother's access to information (access to at least one media). This variable enables checking the likely knowledge of the mother in the area of nutrition and childcare.

\section{5) Household income}

Income is the central variable (or variable of interest) of our study. This is one of the most significant variables of child health [16] [30] [31] and, to a certain extent, it determines the amount of other inputs (food, shelter clothing, health care, etc.). The relationship between the child's nutritional status, represented by the height for age and income, has been the subject of many studies having led to very mixed results [32]. Unfortunately income and household consumption is not available to us. Instead, we use a wealth index as a proxy for the long-term income of households. This index has been constructed using the information relating to durable goods owned by households ${ }^{5}$. The aggregation methodology ${ }^{6}$ is based on the approach of multiple correspondence analysis [33] [34]. Subsequently, this index is broken down into five socio-economic classes (poorest, poor, average, rich, richest) as a function of goods owned. These classes correspond respectively to the first, second, third, fourth and fifth quintile. The resulting breakdown could enlighten us as to whether or not structural changes exist with respect to variation in the height for age based on the household resources [4].

\subsubsection{The Characteristics of the Environment or the Community}

The effects of the environment (or the community) on the child's health are well documented in the theoretical literature. The famous model of Mosley-Chen [35], the economic model of the family by Becker [36] and the production function of health by Grossman [37] have shown the direct or indirect impact of community factors on infant health. In our case, in light of the available data, the essentials are access to drinking water, electricity, housing: the presence or absence of a modern toilet, type of floor (cement). There are many studies that have highlighted the importance of these infrastructures for childhood pathologies, and subsequently for malnutrition, on the health of the child. For example, access to drinking water, and the existence of modern toilets and a cement floor to avoid many diseases, particularly intestinal, which affect the child's growth [19]. In addition, there are also the variables of spatial localisation such as the place or region of residence. The environment is different from one region to another; and, in many developing countries, there is often an unequal distribution of the social and health infrastructures between rural and urban areas. Some studies have also taken into account this aspect and analyses have been done based sometimes on separate samples: urban, rural and national.

\section{Method of Analysis}

\subsection{Functional Forms}

Two functional forms are often used. In the first, the probability for a child of having a risk to growth is described by a logistic model: $\operatorname{Pr}\left(z_{i}=1\right)=\frac{\exp \left(x_{i} \beta\right)}{1+\exp \left(x_{i} \beta\right)}$ and $\operatorname{Pr}\left(z_{i}=0\right)=1-\operatorname{Pr}\left(z_{i}=1\right)$; where $z_{i}=1$ if the child $i$ has a delay of growth and $z_{i}=0$ otherwise. The second form is the following linear model:

\footnotetext{
${ }^{5}$ The following variables were excluded from the wealth index: access to water and electricity, type of toilet and the type of floor. They are taken into account separately because they are related to both the collective facilities and to the heritage of the household.

${ }^{6}$ Principal component analysis is used by numerous researchers.
} 
$z_{i}=x_{i} \beta+e_{i} ; x_{i}$ is the vector of explanatory variables that may be exogenous or endogenous. In this study, only the second functional form is considered.

\subsection{Selection Bias and Empirical Specification}

The linear model can be estimated by ordinary least squares. However, this regression suffers from a few statistical problems likely to create bias in the estimates. In fact, in our sample, only the children alive at the time of the survey could have been measured: there is therefore a selection bias to the extent that it can be assumed that there is no total independence between the fact of being alive and health status [19]. In a country like Congo where infant and child mortality is high, it is possible that some children from our database could have been dying of hunger. It could be said the children in our sample possess particular features: more resistant, better fed, taller, which might distort the estimates. The mechanism of selection assumes that the empirical fact of surviving $(s)$ is determined by a latent variable (non-observable) $s^{*}$ as follows:

$$
S_{i}=\left\{\begin{array}{ll}
1 & \text { if } s_{i}^{*} \geq 0 \\
0 & \text { if } s_{i}^{*}<0
\end{array} \text { with } s_{i}^{*}=w_{i} \gamma+u_{i}\right.
$$

where $w_{i}$ is a vector of explanatory variables of survival and $u_{i}$ an error term. That being so, the estimation of the linear model is therefore conditioned by the survival of the child, i.e. $s_{i}=1$, which causes the bias. An empirical strategy exists for correcting this bias [29]. We use the following selection model:

$$
\begin{aligned}
& s_{i}^{*}=w_{i} \gamma+u_{i} \\
& s_{i}=1\left[s_{i}^{*} \geq 0\right] \\
& z_{i}=x_{i} \beta+e_{i}, \text { observed if } s=1
\end{aligned}
$$

As can be seen, one is confronted with a system of simultaneous equations, in which one of them can only be estimated on a sub-sample depending on a system determined by the other. By involving a fully parametric characterisation of the system, assuming the joint normality of error terms of the two equations, the model can be estimated by the maximum-likelihood method [38]. Nevertheless, we often use the Heckman two step estimation procedure instead [39].

\section{Results}

It should first be noted that we used the Nakamura test, to check the endogeneity of some variables. The lack of necessary instruments has led us to consider some of them as exogenous. This is, for example, the case of the variables related to the household composition. The endogenous nature of other variables has been taken into account by applying the two stage regression procedure. Moreover, the problem of heteroscedasticity has been resolved using White's correction. Finally, the Heckit procedure in Stata software has allowed us to reject the hypothesis of a selection bias in our sample. In the analysis of the results, it can be seen that the explanatory powers of the models measured by $R^{2}$ are low but consistent with those found in previous works, taking into account the fact that the health status of a population is difficult to measure [8].

\subsection{Direct Relationship between Poverty and the Child's Nutritional Health}

Table 2 gives the results of the regression between the wealth index and the height for age, for all the children and by gender. As can be seen, the impact of the wealth index is positive and highly significant, showing that an increase in the household wealth of $10 \%$, would reduce chronic malnutrition by $6.3 \%$. It can also be noted that the household resources seem to favour girls a little more than boys. The breakdown of the wealth index gives quite interesting results (Table 3). The fact that the child belongs to a very poor household as opposed to a very rich household increases malnutrition. The same observation can be made for poor and intermediate classes. The regression coefficients (in absolute value) tend to decrease when we go from the poorest class to the richest class.

If one takes into account the breakdown of the index by gender, and for significant values (at the threshold of $1 \%$ ), particularly for the poorest class, one sees a substantial gap between the coefficient of the girls and that of the boys. In effect, an increase of one unit of the wealth index deteriorates the height for age of 0.56 units for boys and by 0.44 units among girls. 
Table 2. Relationship height for age index-wealth index.

\begin{tabular}{ccccccc}
\hline & \multicolumn{2}{c}{ All } & \multicolumn{2}{c}{ Boys } & \multicolumn{2}{c}{ Girls } \\
\cline { 2 - 6 } & Coeff. & t-stat & Coeff. & t-stat & Coeff. & t-stat \\
\hline Wealth index & 0.6345185 & $6.06^{* * *}$ & 0.6270308 & $4.43^{* * *}$ & 0.6472413 & $4.15^{* * *}$ \\
Constant & -0.9181392 & $33.53^{* * *}$ & $-9,803,026$ & $-25.68^{* * *}$ & -0.8517949 & $-21.67^{* * *}$ \\
& $\mathrm{~N}=3824$ & $\mathrm{~N}=1973$ & $\mathrm{~N}=1851$ \\
$\mathrm{~F}(1,3822)=36.69$ & $\mathrm{~F}(1,1971)=19.62$ & $\mathrm{~F}(1,1849)=17.23$ \\
$\mathrm{R}^{2}=0.0089$ & \multicolumn{2}{c}{$\mathrm{R}^{2}=0.0089$} & $\mathrm{R}^{2}=0.0091$ \\
\hline
\end{tabular}

${ }^{* * *},{ }^{* *},{ }^{*}$ represent significant coefficients at the $1 \%, 5 \%$ and $10 \%$ respectively.

Table 3. Relationship between height for age index and the classification based on the wealth index

\begin{tabular}{ccccccc}
\hline & \multicolumn{2}{c}{ All } & \multicolumn{2}{c}{ Boys } & \multicolumn{2}{c}{ Girls } \\
\cline { 2 - 7 } & Coeff. & t-stat & Coeff. & t-stat & Coeff. & t-stat \\
\hline Poorest & -0.5036724 & $-4.91^{* * *}$ & -0.5622544 & $-3.98^{* * *}$ & -0.4381149 & $-2.93^{* * *}$ \\
Poor & -0.2899294 & $-2.83^{* * *}$ & -0.4450123 & $-3.16^{* * *}$ & -0.1259365 & -0.84 \\
Average & -0.2983505 & $-2.53^{* *}$ & -0.4338292 & $-2.71^{* * *}$ & -0.1463372 & -0.84 \\
Rich & -0.0588918 & -0.52 & -0.2567768 & $-1.66^{*}$ & 0.1481544 & 0.88 \\
Constant & -0.6220886 & $-6.90^{* * *}$ & -0.5676048 & $-4.62^{* * *}$ & -0.6831544 & $-5.15^{* * *}$ \\
& \multicolumn{2}{c}{$\mathrm{N}=3824$} & $\mathrm{~N}=1973$ & $\mathrm{~N}=1851$ \\
& \multicolumn{2}{c}{$\mathrm{F}(4,3819)=10.04$} & $\mathrm{~F}(4,1968)=4.72$ & $\mathrm{~F}(4,1846)=6.65$ \\
$\mathrm{R}^{2}=0.0101$ & \multicolumn{2}{c}{$\mathrm{R}^{2}=0.0088$} & 0.0142 \\
\hline
\end{tabular}

$\stackrel{* * *}{* * *},{ }^{*}$ represent significant coefficients at the $1 \%, 5 \%$ and $10 \%$ respectively.

\subsection{The Determinants of the Child's Nutritional Health}

In what will follow, we want to assess the net effect of poverty on the child's nutritional health. To do this, we introduced other known control variables. These are in fact the characteristics of the child, the parents, or of the household, community and the environment that we have previously specified. Three regression models are proposed (Table 4).

\subsubsection{The Characteristics of the Child}

The results obtained for the age are consistent with the literature. We found the coefficients significant at the $1 \%$ threshold: negative for the age and positive for age squared. As regards the gender, one obtains significant negative coefficients at the threshold of $1 \%$. This result thus confirms the results of Svedberg on the absence of bias against girls.

We found that the presence of a twin significantly deteriorates the size. This result is consistent with those of previous works.

An interval between the birth of the child studied and that of the previous child, has a significant and positive effect on its size.

Our study shows that the birth rank has no impact on the child's size. Finally, we note that the integration of the child with its siblings has no impact on its growth.

\subsubsection{Characteristics of the Parents and the Household}

With respect to the characteristics of the mother, the mother's state of health represented by body mass index, has a significant negative impact on the child's growth index. This could reflect the fact that household food security is not guaranteed and deteriorates accordingly the child's nutritional status.

Virtually all the works confirmed the role of the mother's education. This is also the case in our research where this variable has a very significant positive effect on the child's health. An increase of one year in the mother's years of education increases the growth score, all other things being equal, by 0.04. Moreover, it must be emphasized that the fact that the mother knows how to read has no effect on the child's nutritional status: the coefficient of this variable is negative and non-significant (regression model 2). One can interpret this result as 
Table 4. Relationship between height for age index, wealth index and the control variables.

\begin{tabular}{|c|c|c|c|c|c|c|}
\hline & \multicolumn{2}{|c|}{ Model 1} & \multicolumn{2}{|c|}{ Model 2} & \multicolumn{2}{|c|}{ Model 3} \\
\hline & Coeff. & t-stat & Coeff. & t-stat & Coeff. & t-stat \\
\hline \multicolumn{7}{|l|}{ Characteristics of children } \\
\hline Child's age in months & -0.0603463 & $-10.02^{* * *}$ & -0.0602642 & $-10.01^{* * *}$ & -0.0603277 & $-100.01^{* * *}$ \\
\hline Square of the child's age in months & 0.0006875 & $6.80^{* * *}$ & 0.0006859 & $6.79^{* * *}$ & 0.000689 & $6.81^{* * *}$ \\
\hline Child's gender & -0.1347898 & $-2.56^{* *}$ & -0.1355429 & $-2.57^{* *}$ & -0.1314197 & $-2.49^{* *}$ \\
\hline Child's birth rank & -0.0169985 & -0.25 & -0.0165796 & -0.24 & -0.013153 & -0.19 \\
\hline $\begin{array}{l}\text { Interval in months separating the child considered from } \\
\text { the next oldest child }\end{array}$ & 0.004184 & $3.72^{* * *}$ & 0.0041986 & $3.73^{* * *}$ & 0.0041768 & $3.70^{* * *}$ \\
\hline The presence of a twin & -0.8650292 & $-5.23^{* * *}$ & -0.8665762 & $-5.23^{* * *}$ & -0.8491915 & $-5.12^{* * *}$ \\
\hline The number of children in the household & 0.0004628 & 0.03 & 0.0004461 & 0.03 & -0.0003524 & -0.02 \\
\hline The number of children under age 5 in the household & -0.0328394 & -0.65 & -0.0324841 & -0.65 & -0.0315158 & -0.63 \\
\hline \multicolumn{7}{|l|}{ Characteristics of the household } \\
\hline Mother's education (years of studies) & 0.0361313 & $3.98^{* * *}$ & 0.0344436 & $3.63^{* * *}$ & 0.0362409 & $3.99^{* * *}$ \\
\hline The wife has access to at least one media & 0.033885 & 0.45 & & & 0.0174828 & 0.23 \\
\hline The wife knows how to read & & & -0.0258781 & -0.35 & & \\
\hline The mother's age at the first birth & 0.0131173 & 1.09 & 0.013266 & 1.11 & 0.0136326 & 1.13 \\
\hline The mother's age (at the time of the birth) & 0.0030219 & 0.31 & 0.0027995 & 0.29 & 0.0030985 & 0.32 \\
\hline The mother's health status (body mass index) & -0.0043082 & $-2.53^{* *}$ & -0.0043145 & $-2.54^{* *}$ & -0.0041726 & $-2.46^{* *}$ \\
\hline Family situation (single parent family) & -0.0545196 & -0.75 & -0.0547773 & -0.75 & -0.0486887 & -0.67 \\
\hline Family situation (polygamous family) & -0.0924776 & -1.15 & -0.0918426 & -1.14 & -0.0917358 & -1.13 \\
\hline Wealth index (household income) & 0.4357158 & $2.86^{* * *}$ & 0.4432275 & $2.91^{* * *}$ & & \\
\hline \multicolumn{7}{|l|}{ Socio-economic classification } \\
\hline Poorest & & & & & -0.2930593 & $-2.19^{* *}$ \\
\hline Poor & & & & & -0.1416679 & -1.12 \\
\hline Average & & & & & -0.1607942 & -1.26 \\
\hline Rich & & & & & 0.0144374 & 0.12 \\
\hline \multicolumn{7}{|l|}{ Characteristics of environment/community } \\
\hline The household has access to drinking water & -0.0776559 & -1.05 & -0.0768514 & -1.04 & -0.070348 & -0.95 \\
\hline The household has electricity & -0.0828471 & -1.06 & -0.0813175 & -1.05 & -0.0594063 & -0.76 \\
\hline Type of toilet in the household & 0.1608071 & $2.10^{* *}$ & 0.161577 & $2.10^{* *}$ & 0.1723039 & $2.26^{* *}$ \\
\hline Type of floor in the household & 0.0404869 & 0.54 & 0.0394338 & 0.53 & 0.0284875 & 0.38 \\
\hline \multicolumn{7}{|l|}{ - Place of residence } \\
\hline Rural & -0.269182 & $-2.88^{* * *}$ & -0.2713925 & $-2.91^{* * *}$ & -0.2618085 & $-2.81^{* * *}$ \\
\hline \multicolumn{7}{|l|}{ - Region of residence } \\
\hline Brazzaville & -0.1898967 & $-2.33^{* *}$ & -0.188974 & $-2.32^{* *}$ & -0.2012345 & $-2.47^{* *}$ \\
\hline South & 0.2215025 & $2.17^{* *}$ & 0.2223461 & $2.17^{* *}$ & 0.2082142 & $0.04^{* *}$ \\
\hline North & 0.1044212 & 0.97 & 0.1065899 & 0.99 & 0.0796651 & 0.74 \\
\hline \multirow[t]{4}{*}{ Constant } & -0.0858426 & -0.29 & -0.0380752 & -0.13 & 0.0489823 & 0.15 \\
\hline & \multicolumn{2}{|c|}{$\mathrm{N}=3824$} & \multicolumn{2}{|c|}{$\mathrm{N}=3824$} & \multicolumn{2}{|c|}{$\mathrm{N}=3824$} \\
\hline & \multicolumn{2}{|c|}{$\mathrm{F}(24,3799)=17.48$} & \multicolumn{2}{|c|}{$F(24,3799)=17.45$} & \multicolumn{2}{|c|}{$F(27,3796)=15.61$} \\
\hline & \multicolumn{2}{|c|}{$\mathrm{R}^{2}=0.0948$} & \multicolumn{2}{|c|}{$\mathrm{R}^{2}=0.0949$} & \multicolumn{2}{|c|}{$\mathrm{R}^{2}=0.0953$} \\
\hline
\end{tabular}

***, **, , represent significant coefficients at the $1 \%, 5 \%$ and $10 \%$ respectively. 
follows: "knowing how to read and write in a language without attending a formal school is not enough to put into practise the lessons received in the area of nutrition and child care".

By including the variable "access to at least one media”, we wanted to confirm the argument of Thomas, Strauss and Henriques [12] according to which, the influence of maternal education may be interpreted by a better understanding and reception of the information necessary to improve the child's health; and in this case, given the mother's level of education and the household resources, access to different media should play a positive role. This hypothesis is rejected in the case of our sample. The variable access to the media has a positive effect, however, it is not significant (Model 2 and 3).

We found that the family status of women does not intervene in the child's development. The fact that the woman lives alone, or in a polygamous union, has no impact on the child's nutritional status.

The wealth index always appears as a major determinant of the child's nutritional status. Its coefficient remains high and very significant. As of now, an increase in the household wealth of $10 \%$, would reduce chronic malnutrition by $4.3 \%$. This result is close to that obtained by [3], for Benin (4\%), but very much higher than that found by [4] for Bangladesh, namely $0.8 \%$. It will also be noted, that the effect of the wealth index has a great impact on that of education.

\subsubsection{The Characteristics of the Environment (or the Community)}

Some studies have found a reasonably solid connection between access to water and electricity and the nutritional status of the child. In contrast to these studies, in the sample from the Demographic and Health Survey of Congo, these two variables are not significant factors in the child's growth. Most of the coefficients on these two variables are negative, that is to say they do not have the expected sign. It should be noted that access to safe drinking water and electricity depends in general on the state through their national companies for distribution of water and electricity. One can therefore be connected to these distribution networks and not have water or electricity during a good period of the year.

With regard to the two variables on the housing, characterising the household living conditions, only the provision of a modern toilet has a positive and significant impact on the child's growth. The coefficient of the variable type of floor (cement), although having the expected signs is not significant at the thresholds selected.

We found that the children in rural areas are disadvantaged in size by 0.3 SD compared to those in an urban environment.

Finally, we note the existence of a regional dimension of malnutrition. If you take the city of Pointe-Noire (economic capital of the country) as a reference, we found that the children living in the southern part of the country are favoured. An opposite effect is observed in Brazzaville (political capital of the country) whose children are disadvantaged by 0.2 SD compared to those in Pointe-Noire.

\section{Conclusions and Recommendations}

The objective of this study was to explore the relationship between poverty and the nutritional health of the child based on the data from the first Demographic and health survey of Congo carried out in 2005. Beyond this relationship, we wanted to analyze the determinants of the child's nutritional status and to base it on the specific characteristics of the child, the household and the parents, and on the characteristics of the environment or the community. To this effect, regression models have been proposed and have shown that several variables had a significant impact on the child's nutritional status. The public authorities could therefore take advantage of these results to, in particular, combat malnutrition of children and, in general, fight against poverty. From this study, and in view of the econometric tests performed, we could draw the main conclusions as follows:

- firstly, the study has shown that an increase of the wealth index of households very significantly improved the nutrition of children; that this strong improvement will benefit girls a little more than boys. In the light of the breakdown of this index, it could be suggested that a public policy of transfer, that is to say, which would alter the distribution of income in favour of the poorest (the poorest quintile) could be most effective;

- secondly, the results of the study suggest reflections focused on the health and education of women. First, the study has highlighted the negative role of the mother's health (through the body mass index) on the child's growth, testifying to the importance of household food insecurity. We know that the repetition of closely spaced births weakens the mother. Increasing the gaps between the births would therefore be a fundamental element for improving the health of the child and the dissemination of contraception means would 
be a key objective in this case. Then, the study has confirmed the role of maternal education in reducing child malnutrition because an educated mother better understands the teachings on child nutrition. The public authorities could therefore improve the living conditions of children by adopting a well-targeted policy concerning certain expenditures for health and education; finally, the study revealed a regional dimension of malnutrition. A policy of intervention aimed at improving the conditions of community life in rural areas and Brazzaville would be desirable.

\section{References}

[1] Linnemayr, S. and Aldeman, H. (2006) Determinants of Malnutrition in Senegal: Individual, Household, Community Variables, and Their Interaction. World Bank, Washington DC.

[2] Appaix, T. (2003) Impact économique de l'investissement dans la santé de l'enfant, Communication pour les XXVIèmes journées des économistes français de la santé.

[3] Ahovey, E.C. and Vodounou, C. (2004) Pauvreté multidimensionnelle et santé de l'enfant: Quelques évidences de l'enquête démographique et de santé du Bénin de 2001. INSAE, Bénin.

[4] Grira, H. (2007) Les déterminants du statut nutritionnel au Matlab: Une analyse empirique. Centre d’Economie de la Sorbonne, CES Working Paper No. 39.

[5] Penders, C.L. Staatz, J.M. and Teft, J.F. (2000) How Does Agricultural Development affect Child Nutrition in Mali? Policy Synthesis. Global Bureau, Office of Agriculture and Food Security, USAID.

[6] CNSEE and ORC Macro (2005) Enquête Démographique et de Santé du Congo, Calverton, Maryland, USA.

[7] Maire, B. Delpeuch, F. Martin-Prevel, Y. and Fouéré, T. (2001) Nutrition et Pauvreté. Bilan comparatif des enquêtes anthropométriques en Afrique Subsaharienne au cours des deux dernières décennies. In: Inégalités et politiques publiques en Afrique: Pluralité des normes et jeux d'acteurs, IRD, Karthala.

[8] Behrman, J.R. and Deolalikar, A.B. (1988) Health and Nutrition. In: Chenery, H. and Srinivan, T.N., Eds., Handbook of Development Economics, Amsterdam, North Holland, 1, 631-711.

[9] Gibson, J. (2000) Child Height, Household Resources, and Household Survey Method. University of Waikato, Waikato.

[10] Strauss, J. and Thomas D. (1995) Human Resources: Empirical Modeling of Household and Family Decisions. In: Behrman, J. and Srinivasan, T.N., Eds., Handbook of Development Economics, Elsevier, Amsterdam, 3A, 1883-2023. http://dx.doi.org/10.1016/s1573-4471(05)80006-3

[11] Waterlow, J.C., Buzina, R., Keller, W., Lane, J.M., Nichman, M.Z. and Tanner, J.M. (1977) The Presentation and Use of Height and Weight Data for Comparing the Nutritional Status of Groups of Children under the Age of Ten Years. Bulletin of the World Health Organisation, 55, 489-498.

[12] Thomas, D., Strauss, J. and Henriques, M.-H. (1990) Child Survival, Height for Age and Household Characteristics in Brazil. Journal of Development Economics, 33, 197-234. http://dx.doi.org/10.1016/0304-3878(90)90022-4

[13] Glewwe, P. (1999) Why Does Mother's Schooling Raise Child Health in Developing Countries? Evidence from Morocco. The Journal of Human Resources, 34, 124-159. http://dx.doi.org/10.2307/146305

[14] Horton, S. (1988) Birth Order and Nutritional Status: Evidence from Philippines. Economic Development and Cultural Change, 36, 341-354. http://dx.doi.org/10.1086/451655

[15] Lefebvre, P. (2006) Discrimination sexuelle dans les dépenses des ménages: Survol de littérature et évidences empiriques pour le Canada. L'actualité Economique, 32, 119-153. http://dx.doi.org/10.7202/013467ar

[16] Pal, S. (1999) An Analysis of Childhood Malnutrition in Rural India: Role of Gender, Income and Other Characteristics. World Development, 27, 1151-1171. http://dx.doi.org/10.1016/S0305-750X(99)00048-0

[17] Gangadharan, L. and Maitra, P. (2000) Does Child Mortality Reflect Gender Biais? Evidence from Pakistan, University of Melbourne, Parkville.

[18] Behrman, J.R. (1988) Nutrition, Health, Birth Order and Seasonality. Intrahousehold Allocation among Children in Rural India. Journal of Development Economics, 28, 43-62. http://dx.doi.org/10.1016/0304-3878(88)90013-2

[19] Morrisson, C. and Linskens, C (2000) Les facteurs explicatifs de la malnutrition en Afrique subsaharienne. OCDE, Document de travail No. 167.

[20] Svedberg, P. (1990) Undernutrition in Sub-Saharan Africa: Is There a Sex Bias? Journal of Development Studies, 26, 469-489. http://dx.doi.org/10.1080/00220389008422165

[21] Arif, G.M. (2004) Child Health and Poverty in Pakistan. The Pakistan Development Review, 43, 211-238.

[22] Birdsall, N. (1991) Birth Order Effects and Time Allocation. Research in Population Economics, 7, 191-213. 
[23] Handa, S. (1999) Maternal Education and Child Height. Economic Development and Cultural Change, 47, 421-439. http://dx.doi.org/10.1086/452408

[24] Barrera, A. (1990) The Role of Maternal Schooling and Its Interaction with Public Health Programs in Child Health Production. Journal of Development Economics, 32, 69-91. http://dx.doi.org/10.1016/0304-3878(90)90052-D

[25] Strauss, J. (1990) Households, Communities, and Preschool Children’s Nutrition Outcomes: Evidence from Rural Cote d'Ivoire. Economic Development and Cultural Change, 38, 232-261. http://dx.doi.org/10.1086/451791

[26] Fogel, R. (1994) Economic Growth Population Theory and Physiology: The Bearing of Long Term Processes on the Making of Economic Policy. American Economic Review, 84, 369-375.

[27] Schultz, T.P. (1984) Studying the Impact of Household Economic and Community Variables on Child Mortality. In: Mosley, W.H. and Chen, L.C., Eds., Child Survival: Strategies for Research, Population and Development Review, Vol. 10, Population Council, New York, 215-235. http://dx.doi.org/10.2307/2807962

[28] Charasse, C. (1999) La mesure et les déterminants de l'état de santé en Afrique du Sud. Revue d'Economie du Développement, 4, 9-37.

[29] Shariff, A. and Ahn, A. (1995) Mother's Education Effect on Child Health: An Econometric Analysis of Child Anthropometry in Uganda. Indian Economic Review, 30, 203-222.

[30] Behrman, J.R. and Wolfe, B.L. (1987) How Does Mother's Schooling Affect Family Health, Nutrition, Medical Care Usage, and Household Sanitation? Journal of Econometrics, 36, 185-204. http://dx.doi.org/10.1016/0304-4076(87)90049-2

[31] Thomas, D., Strauss, J. and Henriques, M.-H. (1991) How Does Mother Education Affect Child Height? The Journal of Human Resources, 26, 183-211. http://dx.doi.org/10.2307/145920

[32] Gibson, J. (2000) How Can Women's Education Aid Economic Development? The Effect on Child Stunting in Papua New Guinea. University of Waikato, Waikato.

[33] Benzécri, J.-P. (1993) Correspondence Analysis Handbook. Marcel Dekker, CRC Press, New York.

[34] Asselin, L.-M. (2009) Analysis of Multidimensional Poverty. Theory and Case Studies. Springer, New York. http://dx.doi.org/10.1007/978-1-4419-0843-8

[35] Mosley, W.H. and Chen, L.C. (1984) An Analytical Framwork for the Study of Child Survival in Developing Countries. In: Mosley, W.H. and Chen, L.C., Eds., Child Survival: Strategies for Research, Population and Development Review, Vol. 10, Population Council, New York, 25-48.

[36] Becker, G. (1991) A Treatise on the Family. Harvard University Press, Cambridge.

[37] Grossman, G. (1972) On the Concept of Health Capital and Demand of Health. Journal of Political Economy, 80, 224225. http://dx.doi.org/10.1086/259880

[38] Greene, W. (1997) LIMDEP Version 7.0 User’s Manuel. Revised Edition, Econometric Software, Inc., Plainview.

[39] Heckman, J.J. (1979) Sample Selection Bias as a Specification Error. Econometrica, 47, 153-161. http://dx.doi.org/10.2307/1912352 